\title{
Indication that Intracellular Fluorescence Polarization of T Lymphocytes is Cell Cycle Dependent
}

\author{
Naomi Zurgil ${ }^{1,3}$, Mordechai Deutsch ${ }^{1}$, Reuven Tirosh ${ }^{1}$, and Chaya Brodie ${ }^{2}$ \\ ${ }^{1}$ Schottenstein Cellscan Center for Early Detection of Cancer, Physics Dept., Bar-Ilan University, Ramat-Gan \\ 52900, ISRAEL, ${ }^{2}$ Department of Life Sciences, Bar-Ilan University, Ramat-Gan 52900, ISRAEL, and ${ }^{3}$ Medis- \\ El Ltd., Jerusalem, ISRAEL
}

Key words: Cell cycle/Jurkat $\mathrm{T}$ lymphocytes/intracellular fluorescence polarization

\begin{abstract}
$A B S T R A C T$. The degree of depolarization of fluorescence light emitted from an organic dye, used as a molecular probe, is a powerful tool in probing the microenvironment. Polarization measurements of intracellular exogenous fluorescein have been shown to reflect the physiological state of the cells. The relationship between intracellular fluorescein fluorescence polarization (IFFP) and cell cycle, was investigated in the leukemia T-lymphocyte Jurkat cell line. Jurkat $\mathbf{T}$ cells were cultured in increasing cell densities, their cell cycle progression cytometrically monitored and the IFFP measured. At the highest cell density, the subpopulation of cells at the resting phases the $\left(G_{0} / G_{1}\right)$ predominated, and the mean IFFP was $0.186 \pm 0.015$. At the lowest density, with diminished proportion of cells in the $G_{1} / G_{2}$ stages the mean IFFP decreased to $0.126 \pm 0.01$. Treatment of the Jurkat $T$ cell line with phase arrested agents $1 \mu M$ hydroxyurea, or $1 \mu M$ nocodazole, arrests the cells in the $S$ and $G_{2} / M$ phases, respectively. These treated cells exhibit significantly lower IFFP values, mean polarization value 0.140 , as compared to $0.171 \pm 0.009$ in control cells. Preincubation of Jurkat cells in buffer results in accumulation of the cells in the $G_{0} / G_{1}$ phases as well as a parallel increase in IFFP. A characteristic decrease in IFFP was demonstrated upon triggering these cells with Phytohaemagglutinin (PHA). High correlation (Pearson correlation =0.942) was found between percentage of cells in the $G_{0} / G_{1}$ phases and the mean IFFP of the measured cell population. These results may indicate that the intracellular microviscosity of Jurkat $T$ cells as measured by IFFP, is changing over the cell cycle.
\end{abstract}

Fluorescence polarization measurements have been used to characterize various physical parameters of cells. Indeed, specific fluorescence probes have been utilized to measure membrane fluidity (10), rotational relaxation time and changes in cytoplasmic microviscosity.

Fluorescein diacetate (FDA) undergoes fluorochromasia (20) in viable cells. This includes penetration of FDA, its enzymatical hydrolysis which converts it to fluorescein and the accumulation of the latter. The IFFP emitted upon excitation with polarized light has been shown to reflect the cytoplasmic microviscosity of the intracellular proteins and their organizational status.

Changes in IFFP have been detected concurrently

Address for Correspondence: Motti Deutsch, Ph.D., Schottenstein Cellscan Center, Physics Department, Bar-Ilan University, Ramat-Gan 52900, ISRAEL

Tel: 972-3-5344675, Fax: 972-3-5342019

Abbreviations: IFFP, Intracellular fluorescein fluorescence polarization; PHA, Phytohaemagglutinin; FDA, Fluorescein diacetate; TCR, T cell receptor; PBS, Phosphate buffer saline; FCS, Fetal calf serum; FACS, Fluorescence activated cell sorter; DPH, Diphenyl hexatriene; GCSF, Granulocyte colony stimulating factor. with physical alteration of the cells: microviscosity changes induced by varying osmolarity (7), and intracellular changes occurring in the cytoskeleton components of activated cells $(8,9)$.

Certain antigens and plant lectins can induce, differentially, subpopulations of lymphocytes to undergo mitogenesis and proliferate. During the process of $\mathrm{T}$ cell activation, there are early responses occurring within minutes or hours after the initiation of signal transduction, while others may occur days after the stimulation. The early cellular responses may be the direct or indirect result of T cell receptor (TCR) mediated signal transduction. The late cellular responses, such as proliferation, generally result from a complex cascade of gene activation events and the sequential influence of these genes.

Early activation of T lymphocytes by PHA results in a cascade of early events including tyrosine phosphorylation, stimulation of phosphoatidylinositole hydrolysis, $\mathrm{Ca}^{+2}$ mobilization and the induction of early protooncogenes. These events are followed by the increased expression of the genes for interleukine IL-2 and its receptor, leading to cell proliferation.

Stimulation of $\mathrm{T}$ lymphocytes with PHA has also 
been shown to induce changes in membrane fluidity and in IFFP.

Early activation responses of human peripheral lymphocytes as induced by mitogenic or antigenic stimulation can be detected by a characteristic decrease in IFFP $(3,8,9,13,21)$. Changes in IFFP were also evident in fibroblasts following cytokine exposure (15).

Attempts have been made, with varying degrees of success, to correlate the phases of the cell cycle with changing IFFP values $(4,14)$.

In the present work we examined the relationship between IFFP and cell cycle as well the response of the cells to mitogen stimulation as detected by changes in fluorescence polarization.

\section{MATERIALS AND METHODS}

Materials: Hydroxyurea, nocodazole (Calbiochem.) FDA (Riedel-de Haen Ag. Seelze-Hanover), PHA (Wellcome Ltd.), acetic acid (Frutarum).

Modified Dulbecco Phosphate Buffered Saline (PBS) was prepared with the following modifications: osmolality: 330 mosm $/ \mathrm{kg}, \mathrm{Ca}^{+2}$ concentration: $2 \mathrm{mM}$.

PHA was reconstituted in $5 \mathrm{ml}$ of double-distilled water and further diluted ten times. For stimulation $0.1 \mathrm{ml}$ of this solution was added to $1 \mathrm{ml}$ of cell suspension (Final concentration $90 \mu \mathrm{g} / \mathrm{ml}$ ).

FDA solution $(0.6 \mu \mathrm{M})$ was prepared as follows: $50 \mathrm{mg}$ of FDA was dissolved in $5 \mathrm{ml}$ of acetic acid by gently warming and shaking. Ten microlitres of this solution was added to $100 \mathrm{ml}$ of the modified PBS, to which $0.37 \mathrm{~g}$ of $\mathrm{Na}_{2} \mathrm{HPO}_{4.12} \mathrm{H}_{2} \mathrm{O}$ had been added (for correction of the $\mathrm{pH}$ ). Twenty-five $\mathrm{ml}$ of this solution was further diluted in $75 \mathrm{ml}$ of the modified PBS.

Methods: Cell culture. The human leukemic T cell line, Jurkat, were maintained in complete medium, RPMI 1640 (Biological Industries, Israel) supplemented with $10 \%(\mathrm{v} / \mathrm{v})$ fetal calf serum (FCS) (Biological Industries, Israel), $2 \mathrm{mM} \mathrm{L-gluta-}$ mine, $1 \mathrm{mM} \mathrm{Na}$ pyruvate, $50 \mathrm{U} / \mathrm{ml}$ penicillin, and $50 \mu \mathrm{g} / \mathrm{ml}$ streptomycin, in a humidified atmosphere containing 5\% $\mathrm{CO}_{2}$.

For density allocation, the cells were cultured at 5 cell densities $\left(1,2,4,5,7 \times 10^{6} / \mathrm{ml}\right)$ for $24 \mathrm{~h}$, then washed 3 times with modified Dulbeco PBS, and incubated in the same buffer for $1 \mathrm{~h}$ before cell cycle and IFFP measurements.

For phase-arrest, Jurkat $\mathrm{T}$ cells were cultured in complete medium containing $1 \mu \mathrm{M}$ hydroxyurea or $1 \mu \mathrm{M}$ nocodazole for $24 \mathrm{~h}$. Following incubation, the cells were washed 3 times with modified Dulbeco PBS, and incubated in the same buffer for $1 \mathrm{~h}$ before cell cycle and IFFP measurements.

PHA stimulation. T-cells were preincubated in PBS or in complete medium for $12 \mathrm{~h}$. Following preincubation, the cells were resuspended in fresh PBS. Viability checked by Trypan blue was always $>90 \%$. One $\mathrm{ml}$ of cell suspension was mixed with $0.1 \mathrm{ml}$ of stimulant (PHA solution or PBS for control) and incubated for $45 \mathrm{~min}$ at $37^{\circ} \mathrm{C}$.

IFFP measurements. The cell suspension $\left(0.2 \mathrm{ml} ; 5 \times 10^{6}\right.$ cells per $\mathrm{ml}$ ) was introduced into $3 \mathrm{ml}$ of the FDA solution, at $27^{\circ} \mathrm{C}$, and which was formerly placed in the measurements compartment of the spectrofluorometer. The fluorometric measurements were performed on a Perkin Elmer MPF-44 spectrofluorometer equipped with a self built automatic polarimeter. The wavelength of excitation of fluorescein fluorescence was $470 \mathrm{~nm}$, with bandwidth of $20 \mathrm{~nm}$. In order to reduce stray light, an interference filter (Balzers) for $468 \mathrm{~nm}$ was further interposed on the excitation beam. The fluorescence was monitored at $510 \mathrm{~nm}$, with bandwidth of $6 \mathrm{~nm}$. The G-factor which corrects the polarization of the incident fluorescence caused by the detection grating was 0.551 .

After approximately $4 \mathrm{~min}$ of measuring the parallel and normally polarized component of the cell suspension fluorescence, the cells were filtered out by $0.45 \mu \mathrm{m}$ pore size filter (TAMA, Israel) and the suspending solution was immediately returned to a carefully washed cuvette for the determination of the background fluorescence. Subtracting the parallel and normally polarized fluorescence of the suspending solution from those of the cell suspension, yields the intracellular fluorescein fluorescence intensities allowing the calculation of the IFFP defined as:

$$
I F F P=\frac{I^{I I}-G I^{\perp}}{I^{\perp}+G I^{\perp}}
$$

IFFP measurements were repeated in triplicate samples. Each polarization value is an average of three different measurements.

Cell cycle analysis. Cells were washed three times in PBS without $\mathrm{Ca}^{2+}$ and $\mathrm{Mg}^{2+}$ followed by incubation in propidium iodide solution (Sodium citrate $56 \mathrm{mg}$, propidium iodide 215 $\mathrm{mg}, \mathrm{NP} 401 \%$ and RNase $0.5 \mathrm{mg} / \mathrm{ml}$ ), for $15 \mathrm{~min}$ in room temperature. Cells were then analyzed by flow cytometry (Beckton Dickson) with an excitation argon laser wavelength of $488 \mathrm{~nm}, 300 \mathrm{~mW}$.

Statistical analysis. Analysis of correlation between cell cycle phases and IFFP values was carried out by calculating the Pearson correlation coefficient in each case.

\section{RESULTS}

The relationships among cell densities, phases, and IFFP values are shown in Table I. At higher cell densities, there was a greater proportion of cells in the resting phases $\left(\mathrm{G}_{0} / \mathrm{G}_{1}\right)$ and a reduced proportion in the $S$ and $\mathrm{G}_{2} / \mathrm{M}$ phases. As the cell density and percentage of cells in the $\mathrm{G}_{0} / \mathrm{G}_{1}$ stages increased, there was a concomitant and significant increase in IFFP from $0.126 \pm 0.01$ to $0.186 \pm 0.015$ (Table I).

The results of treating the Jurkat $\mathrm{T}$ cell line with specific drugs known to arrest cell cycle progression in specific phases, is demonstrated in Table II. Jurkat cells cultured in the presence of $1 \mu \mathrm{M}$ hydroxyurea moved rapid- 
Table I. Correlation between Cell Density, CELL CYCLE PHASE, AND IFFP.

\begin{tabular}{ccccc}
\hline $\begin{array}{c}\text { Cell density } \\
\left(10^{6} / \mathrm{ml}\right)\end{array}$ & $\begin{array}{c}\text { \% cells in } \\
\mathrm{G}_{0} / \mathrm{G}_{1}\end{array}$ & $\begin{array}{c}\text { \% cells in } \\
\mathrm{S}\end{array}$ & $\begin{array}{c}\% \text { cells in } \\
\mathrm{G}_{2} / \mathrm{M}\end{array}$ & $\begin{array}{c}\text { IFFP } \\
\text { (mean) }\end{array}$ \\
\hline 1 & 51.8 & 42.2 & 6.0 & $0.126 \pm 0.01$ \\
2 & 60.1 & 34.1 & 5.7 & $0.132 \pm 0.009$ \\
4 & 64.8 & 31.2 & 4.0 & $0.150 \pm 0.021$ \\
5 & 65.1 & 32.8 & 2.1 & $0.166 \pm 0.01$ \\
7 & 73.9 & 24.4 & 1.7 & $0.186 \pm 0.015$ \\
\hline
\end{tabular}

Jurkat cells were cultured at different cell densities for $24 \mathrm{~h}$, then washed 3 times with modified Dulbeco PBS, and incubated in the same buffer for $1 \mathrm{~h}$ before cell cycle and IFFP measurements.

ly into the proliferative state, but were arrested at the $\mathrm{S}$ phase. After $24 \mathrm{~h}$, more than $50 \%$ were found in the $\mathrm{S}$ and $\mathrm{G}_{2} / \mathrm{M}$ phases of cell cycle. These hydroxyurea treated cells exhibit a significantly lower mean IFFP, $0.148 \pm 0.012$ in comparison to $0.171 \pm 0.009$ in nontreated cells (Table II).

Similarly, a marked decrease in the number of cells in the $G_{0} / G_{1}$ phases and parallel increase in the percentage of cells in the $S$ and $\mathrm{G}_{2} / \mathrm{M}$ phases was observed $(28 \%$ of cells at the S phase had increased to 53\%) after nocodazole treatment. The mean IFFP value of nocodazoletreated cells $(0.131 \pm 0.014)$ was lower than that of the untreated control cells $(0.171 \pm 0.009)$.

Ten repeated experiments were used for the statistical analysis of the correlations between cell cycle parameters and fluorescence polarization. Statistical analysis revealed that best correlation is observed between values of percentage of cells in the $G_{0} / G_{1}$ phases and the absolute values of mean IFFP of the measured cell population (Table III, Fig. 1).

IFFP values were found to be related to the ability to detect changes in fluorescence polarization induced by stimulation with mitogen. Jurkat T-cells cultured at low density in complete medium and exhibiting regular cell cycle pattern (about $40 \%$ of the cell population in the $\mathrm{G}_{0} / \mathrm{G}_{1}$ phases), did not show any changes in the mean cytoplasmic IFFP following activation with PHA (Fig. 2) but did react to PHA with a decrease in IFFP

Table II. The INFLUENCE OF HYDROXYUREA AND NOCODAZOlE ON JURKAT T CELL CYCLE PROGRESSION AS MONITORED BY IFFP.

\begin{tabular}{lcccc}
\hline Treatment & $\begin{array}{c}\% \text { cells in } \\
\mathrm{G}_{0} / \mathrm{G}_{1}\end{array}$ & $\begin{array}{c}\text { \% cells in } \\
\mathrm{S}\end{array}$ & $\begin{array}{c}\% \text { cells in } \\
\mathrm{G}_{2} / \mathrm{M}\end{array}$ & $\begin{array}{c}\text { IFFP } \\
\text { (mean) }\end{array}$ \\
\hline $\begin{array}{l}\text { Naturally cycling } \\
\quad \text { control) }\end{array}$ & 69.9 & 28.4 & 1.7 & $0.171 \pm 0.009$ \\
Hydroxyurea & 47 & 45 & 8 & $0.148 \pm 0.012$ \\
Nocodazole & 20.4 & 52.8 & 26.8 & $0.131 \pm 0.014$ \\
\hline
\end{tabular}

Jurkat $\mathrm{T}$ cells were cultured in complete medium containing $1 \mu \mathrm{M}$ hydroxyurea or $1 \mu \mathrm{M}$ nocodazole for $24 \mathrm{~h}$. Following incubation, the cells were washed 3 times with modified Dulbeco PBS, and incubated in the same buffer for $1 \mathrm{~h}$ before cell cycle and IFFP measurements.
Table III. Statistical analysis of the CORRELATION BETWEen CELL CYCLE PARAMETERS AND FLUORESCENCE POLARIZATION VALUES IN THE JURKAT T CELL LINE.

\begin{tabular}{cccc}
\hline $\begin{array}{c}\text { Cell Cycle } \\
\text { Phase }\end{array}$ & $\begin{array}{c}\text { Pearson } \\
\text { Correlation }\end{array}$ & $\begin{array}{c}\text { R Correlation } \\
\text { Mean R Squared }\end{array}$ & $\begin{array}{c}\mathrm{p} \\
\text { (2 Tails) }\end{array}$ \\
\hline $\mathrm{G}_{0} / \mathrm{G}_{1}$ & 0.942 & 0.888 & $<0.001$ \\
$\mathrm{~S}$ & -0.886 & 0.07 & 0.46 \\
$\mathrm{G}_{2} / \mathrm{M}$ & -0.265 & 0.785 & 0.001 \\
\hline
\end{tabular}

Mean IFFP values of Jurkat $\mathrm{T}$ cells as a function of the percentage of cells in different phases were obtained from 10 different experiments. In each experiment the measurements were performed in triplicate. Analysis of correlation between cell densities, cell cycle phases, and IFFP was carried out by calculating the $\mathrm{R}$ correlation and Pearson correlation coefficient in each case.

after preincubation of the T cell line in PBS for $12 \mathrm{~h}$. Fluorescence activated cell sorter (FACS) analysis showed that more than $70 \%$ of the cells were in $\mathrm{G}_{0} / \mathrm{G}_{1}$.

\section{DISCUSSION}

When polarized illumination is used to excite a fluorochrome labeled cell, some of the fluorescence is emitted as a depolarized light. The extent of depolarization reflects the molecular fluidity or mobility of the dyebound molecule and therefore would seem to have implications about the structure and function of the microenvironment.

Several studies have suggested a link between cell cycle and various physical parameters of cells expressed

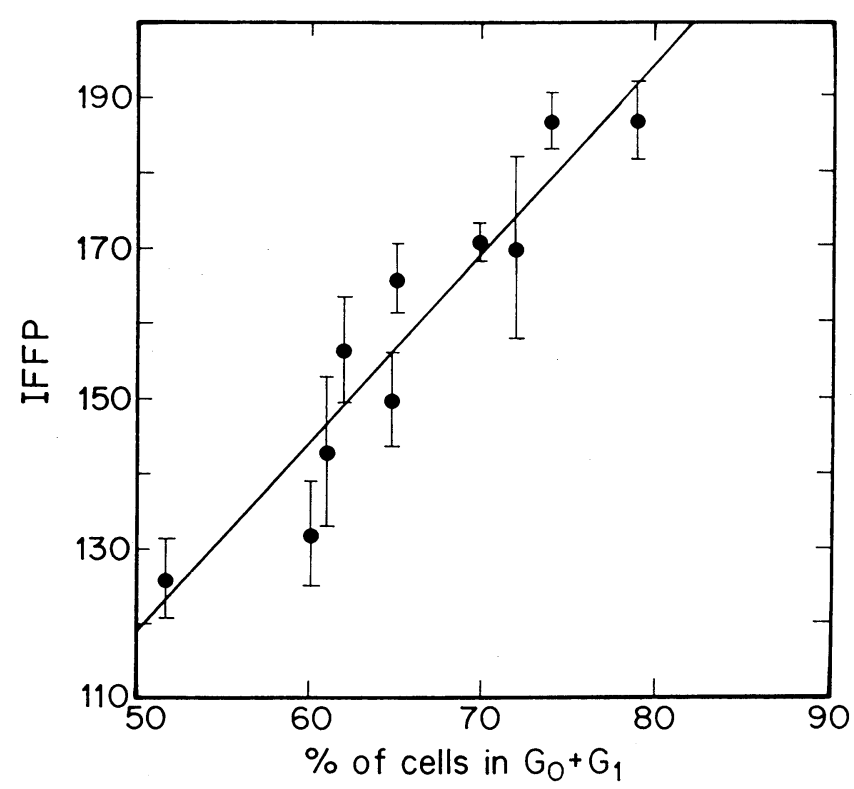

Fig. 1. Mean IFFP values of Jurkat $T$ cells as a function of the percentage of cells in the $G_{0} / G_{1}$ phases. Each IFFP value comprises equal values of $G_{0} / G_{1}$ obtained in different experiments. In each experiment the measurements were performed in triplicate. 


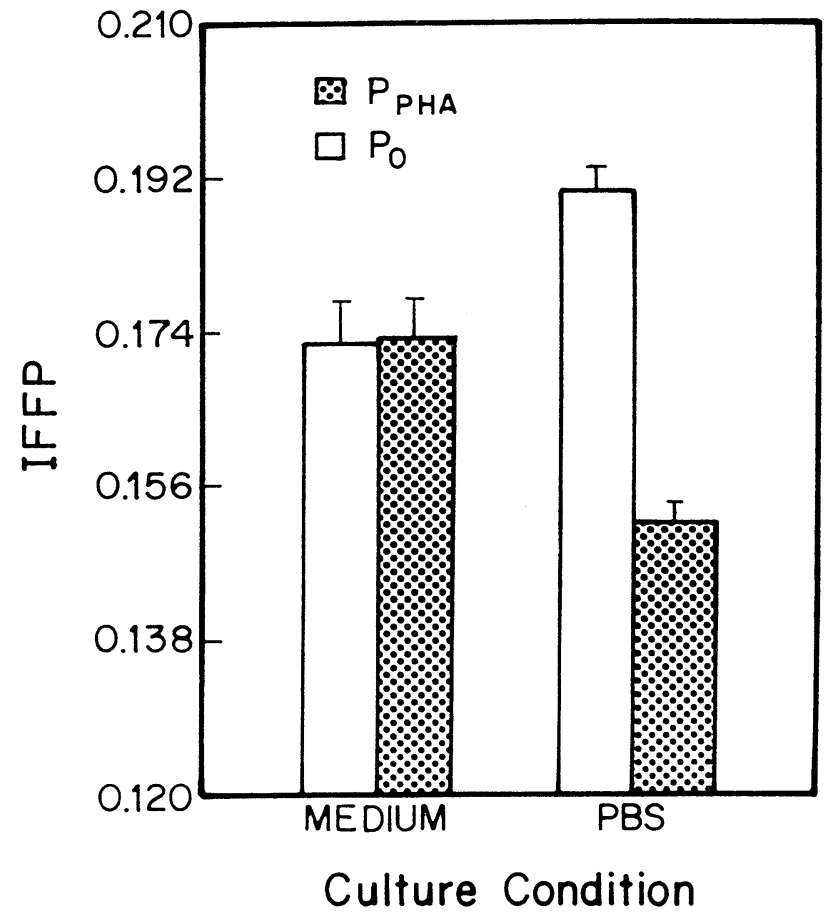

Fig. 2. IFFP values of Jurkat $T$-cells before $\left(\mathrm{P}_{0}\right)$ and after $\left(\mathrm{P}_{\mathrm{PHA}}\right)$ incubation with PHA both for cultured cells at complete medium and cells preincubated in PBS. T-cells were preincubated in complete medium or PBS, for $12 \mathrm{~h}$, resuspended in fresh PBS, and incubated for 45 min at $37^{\circ} \mathrm{C}$ with PHA or PBS for control. Following stimulation, cell cycle and IFFP were measured.

by fluorescence polarization measurements.

Changes in the fluidity of the membrane lipid bilayer during cell cycling were detected by measuring the fluorescence polarization of the hydrophobic probe diphenyl hexatriene (DPH). Maximal membrane fluidity was found during the $\mathrm{G}_{2} / \mathrm{M}$ phases, and minimal during the S phase of K562 cell line (16), while in mitogen stimulated lymphocytes a decrease in fluorescence polarization of the same probe was observed in the course of $\mathrm{G}_{0} / \mathrm{G}_{1}$ transition, and remained unaltered throughout the cycle (17).

An assessment of the structural changes in the intracellular DNA microenvironment by measuring the depolarization of fluorescence light emitted from DNA intercalating dyes such as ethidium bromide and propidium iodide, failed to reveal cycle dependency (1).

The relation between stages of cell cycle and IFFP is controversial. Indeed, Cercek et al., found a sharp emission polarization peak in $510 \mathrm{~nm}$ in cells arrested in $\mathrm{G}_{0}$ or $G_{1}$ phase which disappears when cells are triggered into the DNA synthesis phase $(5,6)$.

In contrast, Lindmo and Steen, using flow cytometric measurements of IFFP on the human NHIK 3025 cell line, did not find any variation in IFFP throughout the cell cycle (14). While in the Cercek study the cells were grown in suspension, NHIK 3025 is an epithelial cell line grown as a monolayer, which undergoes trypsinization reaction in order to obtain single cell suspension. However, such an enzymatic reaction degraded the plasma membrane, a process which can influence the intracellular cytoplasm as well, and takes several hours to recover. In further considering the lack of agreement between these two sets of findings, we note that the excitation light and the emission parameters differ in these two experiments; this is significant in view of the fact that change in IFFP, as originally described in the literature $(4,6)$, is a wavelength-dependent phenomenon.

In our study, the IFFP of Jurkat T-lymphocytes changed over the cell cycle, an especially prominent effect when phase procurement was mediated by differential cell densities (Table I). The mean IFFP value for a high density Jurkat cell population in which approximately $70 \%$ of the cells were in $\mathrm{G}_{0} / \mathrm{G}_{1}$ was 0.171 , but dropped to 0.126 when about $52 \%$ were in $\mathrm{G}_{0} / \mathrm{G}_{1}$.

Our results are in good agreement with those reported by Cercek et al. who found a mean IFFP value of 0.160 for Chinese hamster ovary cells in $G_{1}$ compared to the value of 0.1 for the S-fraction (6).

The phase-arresting drugs, hydroxyurea and nocodazole, were also used for phase selection. Hydroxyurea interferes with DNA synthesis by inhibiting DNA elongation at the replication fork (2) and nocodazole has highly specific anti- microtubular activity (12).

Hydroxyurea has been reported to arrest cells at either the $G_{0} / G_{1}, G_{1} / S$ or $S$ phases of the cell cycle depending on specific cell line. Thus, bone marrow cells were arrested in the $G_{0} / G_{1}$ phases, whereas incubation of endothelial cells with hydroxyurea produced inhibition of DNA synthesis, as well as blocking the cells in the $S$ phase (11). In our preparation, hydroxyurea induced accumulation of the $T$ cells in the $S$ phase as confirmed by FACS. Higher S-fractions (and lower $\mathrm{G}_{0} / \mathrm{G}_{1}$ fractions) were correlated with a marked decrease in the fluorescence polarization values of these cells to a mean of 0.148 (Table II).

Nocodazole has been show to lock proliferating lymphoid cells at the M phase (19). In our study, Jurkat $\mathrm{T}$-cells treated with nocodazole induced cycle arrest in the $\mathrm{G}_{2} / \mathrm{M}$ phases with concomitant reduction in IFFP (Table II).

Environmental conditions are also known to affect the intracellular microenvironment. Thus, in our preparation, changes in IFFP were observed following serum deprivation of $\mathrm{T}$ cells. A high percentage of cells accumulating in the $G_{0} / G_{1}$ phase was found in Jurkat $T$ cell populations after $12 \mathrm{~h}$ incubation in buffer, and a concomitant increase in IFFP was evident. Price et al. demonstrated changes in IFFP of bone marrow cells within a few hours following addition of preparation of Gran- 
ulocyte colony stimulating factor (GCSF) and erythropoetin (18). Other environmental factors such as ion concentrations $\mathrm{Ca}^{+}, \mathrm{K}^{+}$and the concentration of the lectin, were shown to have marked influence on the fluorescence polarization and intensity (22).

IFFP measurements of human peripheral blood lymphocytes have been shown to be a sensitive means of detecting early lymphocyte stimulation $(8,9,13)$.

High correlations were found between cell cycle parameters and mean IFFP values of the Jurkat $\mathrm{T}$ cell line. The strongest correlation found (Pearson correlation $=$ 0.942) was between percentage of cells in $G_{0} / G_{1}$ phases and the mean IFFP of the measured cell population (see also Fig. 1).

The high correlation found in this study between the percentage of cells in the $\mathrm{G}_{0} / \mathrm{G}_{1}$ phases and the absolute values of mean IFFP of the measured cell are notable but not unexpected. The $G_{0} / G_{1}$ phases are sensitive to many factors. The two distinct phases of DNA replication ( $\mathrm{S}$ phase) and mitotic division ( $\mathrm{M}$ phase) are separated by the $G_{1}$ and $G_{2}$ periods during which checkpoints and feedback controls operate to monitor the fidelity and completion of the preceeding stage. Signals from the extracellular milieu, such as growth factors, are transmitted into the cell nucleus through a complex cascade of signal transduction. Only during this phase is the cell sensitive to inadequacies in nutrients or growth factor levels. Failure to satisfy conditions for progress through the cell cycle at these checkpoints, results in cell arrest and possible exit from the cell cycle.

Our data show that IFFP is cell cycle dependent with significantly lower values for cycling than for noncycling populations.

We conclude that changes in IFFP reflect the underlying physical and physiological reality of phase differences as cells progress through the cycle. Such changes should be and are seen to be most prominent in $\mathrm{G}_{1}$ and can also indicate the activation of responsive cells by mitogens, antigens and growth factors.

Continued and increasingly sophisticated technological investigation of the cell cycle, particularly sorting of cells at certain phases (in preparation) will delineate the full nature and extent of its influence on the biophysical quantity, IFFP.

Acknowledgements. We would like to thank Mrs. Pnina Lebowitz for her laboratory assistance.

\section{REFERENCES}

1. Beisker, W. and Eisert, W.G. 1985. Double beam autocompensation for fluorescence polarization measurements in flow cytometry. Biophys. J., 47: 607-612.

2. Boulikas, T. 1992. Poly (ADP-ribose) synthesis in blocked and damaged cells and its relation to carcinogenesis. Anti Can- cer Res., 12: 885-898.

3. CERCEK, L. and CERCEK, B. 1987. Effect of ascorbate ions on Intracellular fluorescein emission polarization spectra in cancer and normal proliferating cells. Cancer Detection and Prevention, 10: 1-20.

4. CerceK, L. and CerceK, B. 1977. Application of the phenomenon of changes in the structuredness of cytoplasmic matrix (SCM) in the diagnosis of malignant disorders. Eur. J. Cancer, 13: 903-915.

5. Cercek, L. and Cercek, B. 1978. Fluorescein excitation and emission polarization specra in living cells. Changes during the cell cycle. Biophys. J., 23: 395-405.

6. CerceK, L., CerceK, B., and OAKLey, L.H. 1973. Structuredness of cytoplasmic matrix and the Michaelis Menton constant for the hydrolysis of FDA during the cell cycles in Chinese hamster ovary cells. Biophysics, 10: 187-194.

7. Deutsch, M. and Weinreb, A. 1994. Apparatus for high precision repetitive sequential optical measurement of living cells. Cytometry, 16: 214-226.

8. Eisenthal, A., Marder, O., Dotan, D., Baron, S., LifschitzMercer, B., Chaitchik, S., Tirosh, R., Weinreb, A., and Deutsch, M. 1996a. Decrease of intracellular fluorescein fluorescence polarization in human peripheral blood lymphocytes undergoing stimulation with phytohaemagglutinin (PHA) concanavalin A (ConA), Pokeweed mitogen (PWM) and anti-CD3. Biology of the Cell, 86 (in press).

9. Eisenthal, A., Marder, O., Lifschitz-Mercer, B., Skornick, Y., Tirosh, R., Weinreb, A., and Deutsch, M. 1966b. Inhibition of mitogen-induced changes in intracellular fluorescein fluorescence polarization of human peripheral blood lymphocytes by colchicine, vinblastine and cytochalasin B. Cell Struc. and Func., 21: 159-166 (in press).

10. Grunberger, D., Haimovitz, R., and Shinitzky, M. 1982. Resolution of plasma membrane lipid fluidity in intact cells labelled with diphenylhexatriene. Biochim. Biophys. Acta., 688: 764-774.

11. GuPta, S.K. and Singh, J.P. 1994. Inhibition of endothelial cell proliferation by platelet factor -4 involves a unique action on S phase progression. J. Cell Biol., 127: 1121-1127.

12. Kaczanowski, A., Gaertig, J., and KubiaK, J. 1985. Effect of the antitubulin drug nocodazole on meiosis and postmeiotic development in Tetrahymena thermophila. Induction of achiasmatic meiosis. Exp. Cell. Res., 158: 244-256.

13. Kaplan, M.R., Trubniykov, E., and Berke, G. 1996. Fluorescence depolarization as an early measure of $\mathrm{T}$ lymphocyte stimulation. J. Immun. Meth. (in press).

14. Lindmo, T. and Steen, H.B. 1977. Flow cytometric measurement of the polarization of fluorescence from intracellular fluorescein in mammalian cells. Biophys. J., 18: 173-187.

15. Marder, O., Shoval, S., Eisenthal, A., Fireman, E., SKornick, Y., LifSChITZ-MERCER, B., DeUTSCH, M., TIRosh, R., and WeINREB, A. 1966. Effect of interleukin (IL)-1 $\alpha$, IL$1 \beta$ and tumor necrosis factor (TNF)- $\alpha$ on the intracellular fluorescein fluorescence polarization (IFFP) of human lung fibroblasts. Pathobiol., 321: 1015-2008 (in press).

16. Muller, C.P. 1989. Cyclic changes in fluorescence polarization of a membrane probe during the cell cycle of erythroid precursor cell line. Exp. Hematol., 17: 1-5.

17. Pajor, L., Kalman, E., and Koszegi, T. 1989. The relationship of membrane fluidity to growth and nuclear cycle in mitogen stimulated lymphocytes. Acta. Biol. Hung., 40: 355-367.

18. Price, G.B., Mccutcheon, M.J., Taylor, W.B., and Miller, R.G. 1977. Measurement of cytoplasmic fluorescence depolari- 
zation of single cells in a flow system. J. Histochem. Cytochem., 25: $597-600$.

19. Reed, J.C., TanaKa, S., and Cuddy, M. 1992. Cell cycle analysis of P26-BC6-2 protein levels in proliferating lymphoma and leukemic cell lines. Cancer Res., 52: 2802-2805.

20. Rotman, B. and Papermaster, B.W. 1966. Membrane properties of living mammalian cells as studied by enzymatic hydrolysis of fluorogenic esters. Proc. Natl. Acad. Sci. USA, 55: 134141.
21. Ron, I.G., Deutsch, M., Tirosh, R., Weinreb, A., Eisenthal, A., and CHAITCHIK, S. 1995. Fluorescence polarization changes in lymphocyte cytoplasm as diagnostic test for breast carcinoma. Eur. J. Cancer, 31A: 917-920.

22. UdKoff, R., Chan, S., and Norman, A. 1981. Identification of mitogen responding lymphocytes by fluorescence polarization. Cytometry, 1: 265-271.

(Received for publication, August 6, 1996) 